Un homme, deux cultures. Charles de Villers entre France et Allemagne (1765-1815), dir. N. BRUCKER et F. MEIER

\title{
Debora Sicco
}

\section{OpenEdition}

\section{Journals}

\section{Edizione digitale}

URL: https://journals.openedition.org/studifrancesi/31793

DOI: 10.4000/studifrancesi.31793

ISSN: 2427-5856

\section{Editore}

Rosenberg \& Sellier

\section{Edizione cartacea}

Data di pubblicazione: 1 août 2020

Paginazione: 407

ISSN: 0039-2944

\section{Notizia bibliografica digitale}

Debora Sicco, «Un homme, deux cultures. Charles de Villers entre France et Allemagne (1765-1815), dir. N. BRUCKER et F. MEIER», Studi Francesi [Online], 191 (LXIV | II) | 2020, online dal 01 septembre 2020,

consultato il 18 septembre 2021. URL: http://journals.openedition.org/studifrancesi/31793 ; DOI: https://doi.org/10.4000/studifrancesi.31793

Questo documento è stato generato automaticamente il 18 septembre 2021.

\section{(†)

Studi Francesi è distribuita con Licenza Creative Commons Attribuzione - Non commerciale - Non opere derivate 4.0 Internazionale. 


\title{
Un homme, deux cultures. Charles de Villers entre France et Allemagne (1765-1815), dir. N. BRUCKER et F. MEIER
}

\author{
Debora Sicco
}

\section{NOTIZIA}

Un homme, deux cultures. Charles de Villers entre France et Allemagne (1765-1815), dir. N. BRUCKER et F. MEIER, Paris, Classiques Garnier, 2019, 332 pp.

1 Il volume rinvia, fin dal titolo, al fondamentale ruolo di mediatore culturale svolto da Charles de Villers, esiliato in Germania nel 1791 per aver preso pubblicamente posizione contro la Rivoluzione francese e presto divenuto un convinto apologeta della nuova patria. Oltre che per la sua attività di intermediazione culturale, Villers è noto per aver tradotto in francese le opere di Kant; egli merita tuttavia di essere ricordato anche per molte altre ragioni, che spaziano dalle opinioni da lui espresse in articoli di giornale o in voci di dizionari al suo interesse per la medicina, dalle sue relazioni con altri esponenti della République des Lettres ai suoi anni di insegnamento a Göttingen. Il presente volume, frutto di un incontro fra ricercatori francesi e tedeschi avvenuto a Metz nel 2015, si articola in cinque parti principali, in cui si esplorano rispettivamente l'attività mediativa di Villers, il suo ruolo nella République des Lettres, i suoi incontri più significativi, il suo impegno di scrittore e giornalista e la sua interpretazione della Riforma.

2 L'importante funzione svolta da Villers nella diffusione di una nuova immagine della letteratura e della filosofia tedesca, evidenziata nel contributo di Hans-Jürgen LÜsEBRINK (Charles de Villers traducteur, médiateur interculturel et auteur traduit, pp. 25-42), è rimarcata anche da Franziska MEIER, che osserva come «dans sa médiation interculturelle, les deux pays finissent pas s'opposer et par se ranger dans une hiérarchie qui atteste la supériorité allemande» («Enfin j’ai été vaincu, jeté à bas de 
mon cheval, j'ai vu la lumière, et je suis devenu apôtre». À propos du "Coup d'œil sur les universités et le mode d'instruction publique de l'Allemagne protestante" de 1808, pp. 57-70, qui p. 65). Questo approccio appare ancor più singolare se lo si confronta con quello adottato da Madame de Staël nel De l'Allemagne. La loro corrispondenza e il loro incontro a Metz, nell'autunno del 1803, sono presi in esame da Marie-Claire нооскDEMARLE (Conversations entre émigré et éxilée. L'Allemagne au cœur de la correspondance entre Charles de Villers et Germaine de Staël, pp. 43-56) e da Monique BERNARD (Le «drame de Metz». Villers et Madame de Staël, pp. 133-150); essi testimoniano come, al di là del complesso rapporto instauratosi fra loro, non privo di una componente sentimentale, Villers abbia, «par sa personne, ses conseils et ses recommandations littéraires [...] influencé directement et profondément sa [di Madame de Saël] réception de l'Allemagne, plus que n'importe lequel de ses informateurs» (p. 147). Altre relazioni degne di nota prese in considerazione nel volume sono quelle che Charles de Villers intrattenne con l'editore Christophe-Gabriel Collignon, con Jean-Baptiste Suard, con il bibliotecario di Treviri Wyttenbach e con Benjamin Constant, con il quale - come mostra Kurt KLOоCKE in Benjamin Constant et Charles de Villers, ou les Dioscures philosophes (pp. 151-162) - Villers, dopo l'incontro di Metz, è rimasto in contatto per tutta la vita e con il quale ha condiviso l'interesse per la politica e la religione.

3 Tutto ciò non esaurisce ancora l'intensa attività di Villers, che può essere anche considerato il fondatore della letteratura comparata (si pensi all'Érotique comparée, qui presa in esame da Catriona SETH, in Bouquets et greffes. "L'Érotique comparée" de Villers, pp. 195-214) e che ha studiato gli effetti della Riforma, interpretandola come un fattore di progresso per la civiltà europea, come ben illustrano nei loro contributi Catherine JULLIARD (Charles de Villers et son "Essai sur la Réformation". Une vision kantienne de l'histoire?, pp. 277-294) et Martin KESSLER (Les théories de la Réforme autour de 1800. Charles de Villers et le concours de l'Institut national de France, pp. 259-276). Un rapidissimo cenno merita anche la corrispondenza di Villers con l'inventore dell'omeopatia Hahnemann (oggetto del contributo di Nicolas BRUCKER, Vis naturae medicatrix. Villers et Hahnemann, pp. 163-178), che testimonia l'interesse di Villers per il magnetismo animale e la sua partecipazione al dibattito europeo sulla medicina alternativa.

Nel complesso, il volume ha il pregio di far luce sulle tante e diverse sfaccettature della produzione letteraria di questo personaggio piuttosto complesso, con un duplice beneficio. Esso, infatti, consente a chi conosce poco o nulla Villers di scoprire i tratti salienti della sua biografia, della sua opera, dei suoi molteplici interessi e, nel contempo, offre una visione più completa dell'autore agli specialisti che ne affrontano lo studio soltanto nella prospettiva di uno specifico ambito disciplinare. Questi risultati sono stati raggiunti grazie agli sforzi congiunti di più studiosi, e non sarebbe forse stato possibile altrimenti, soprattutto in assenza di un'edizione critica di tutte le opere di Villers. 